\title{
Evaluation of high-dose daptomycin for therapy of experimental Staphylococcus aureus foreign body infection Heinz J Schaad ${ }^{2}$, Manuela Bento ${ }^{1}$, Daniel P Lew ${ }^{1}$ and Pierre Vaudaux*1
}

\author{
Address: ${ }^{1}$ Service of Infectious Diseases, Geneva University Hospital, 24 rue Micheli-du-Crest, CH-1211 Geneva 14, Switzerland and ${ }^{2}$ Spital \\ Interlaken, Weissenaustrasse 27, 3800 Unterseen, Switzerland \\ Email: Heinz J Schaad - heinz.schaad@spitalfmi.ch; Manuela Bento - manuela.bento@genomic.ch; Daniel P Lew - daniel.lew@hcuge.ch; \\ Pierre Vaudaux* - pierre.vaudaux@hcuge.ch \\ * Corresponding author
}

Published: II April 2006

BMC Infectious Diseases2006, 6:74 doi:10.1 186/147I-2334-6-74

This article is available from: http://www.biomedcentral.com/I47/-2334/6/74

(C) 2006Schaad et al; licensee BioMed Central Ltd.

This is an Open Access article distributed under the terms of the Creative Commons Attribution License (http://creativecommons.org/licenses/by/2.0), which permits unrestricted use, distribution, and reproduction in any medium, provided the original work is properly cited.
Received: 17 February 2006

Accepted: II April 2006

\begin{abstract}
Background: Daptomycin is a novel cyclic lipopeptide whose bactericidal activity is not affected by current antibiotic resistance mechanisms displayed by $S$. aureus clinical isolates. This study reports the therapeutic activity of high-dose daptomycin compared to standard regimens of oxacillin and vancomycin in a difficult-to-treat, rat tissue cage model of experimental therapy of chronic S. aureus foreign body infection.
\end{abstract}

Methods: The methicillin-susceptible S. aureus (MSSA) strain 120 is a clinical isolate from catheterrelated sepsis. MICs, MBCs, and time-kill curves of each antibiotic were evaluated as recommended by NCCLS, including supplementation with physiological levels $(50 \mathrm{mg} / \mathrm{L})$ of $\mathrm{Ca}^{2+}$ for daptomycin. Two weeks after local infection of subcutaneously implanted tissue cages with MSSA 120, each animal received (i.p.) twice-daily doses of daptomycin, oxacillin, or vancomycin for 7 days, or was left untreated. The reductions of CFU counts in each treatment group were analysed by ANOVA and Newman-Keuls multiple comparisons procedures.

Results: The MICs and MBCs of daptomycin, oxacillin, or vancomycin for MSSA strain 120 were 0.5 and I, 0.5 and I, or I and $2 \mathrm{mg} / \mathrm{L}$, respectively. In vitro elimination of strain 120 was more rapid with $8 \mathrm{mg} / \mathrm{L}$ of daptomycin compared to oxacillin or vancomycin. Twice-daily administered daptomycin $(30 \mathrm{mg} / \mathrm{kg})$, oxacillin $(200 \mathrm{mg} / \mathrm{kg})$, or vancomycin $(50 \mathrm{mg} / \mathrm{kg}$ vancomycin) yielded bactericidal antibiotic levels in infected cage fluids throughout therapy. Before therapy, mean $( \pm$ SEM) viable counts of strain 120 were $6.68 \pm 0.10 \log _{10} \mathrm{CFU} / \mathrm{mL}$ of cage fluid $(n=74)$. After 7 days of therapy, the mean $\left( \pm\right.$ SEM) reduction in viable counts of MSSA 120 was $2.62( \pm 0.30) \log _{10}$ CFU/ $\mathrm{mL}$ in cages $(\mathrm{n}=18)$ of daptomycin-treated rats, exceeding by $>2$-fold $(P<0.0 \mathrm{I})$ the viable count reductions of $0.92( \pm 0.23 ; n=19)$ and $0.96( \pm 0.24 ; n=18) \log _{10} C F U / m L$ in cages of oxacillintreated and vancomycin-treated rats, respectively. Viable counts in cage fluids of untreated animals increased by $0.48( \pm 0.24 ; n=19) \log _{10} \mathrm{CFU} / \mathrm{mL}$.

Conclusion: The improved efficacy of the twice-daily regimen of daptomycin $(30 \mathrm{mg} / \mathrm{kg}$ ) compared to oxacillin $(200 \mathrm{mg} / \mathrm{kg})$ or vancomycin $(50 \mathrm{mg} / \mathrm{kg})$ may result from optimisation of its pharmacokinetic and bactericidal properties in infected cage fluids. 


\section{Background}

Infections due to Staphylococcus aureus associated with foreign implants, such as orthopaedic prostheses and intravascular devices, are very difficult to manage by antimicrobial therapy alone and frequently require the removal of infected materials [1]. The growing proportion of clinical isolates of methicillin-resistant $S$. aureus (MRSA) displaying multidrug resistance not only against all semi-synthetic penicillins and penems, but also frequently against macrolides, aminoglycosides, fluoroquinolones [2-4], and glycopeptides [3,5-7] recently prompted the development of novel antimicrobial agents active against such dangerous pathogens.

Among recently developed agents overcoming antibiotic resistance in MRSA but also highly active against methicillin-susceptible staphylococci, the lipopeptide daptomycin [8-11] was already discovered in the 1980s by Lilly Research Laboratories that stopped its clinical development in 1991 due to reports of potential skeletal muscle toxicity. In 1997, daptomycin development was resumed by Cubist Pharmaceuticals [12] and its clinical use approved by FDA in 2003 for the treatment of complicated skin and soft tissue infections (CSSSIs) [11,13]. Daptomycin is known to exhibit calcium-dependent binding to bacterial cytoplasmic membranes which leads to disruption of membrane function [14]. Daptomycin is uniformly potent in vitro against $S$. aureus clinical isolates in large surveillance studies [11,15-18]. An interesting property of daptomycin is its rapid bactericidal activity in vitro $[9,12,19,20]$ and in vivo $[9,21-23]$, but this bactericidal activity is concentration-dependent and its optimal expression may sometimes require levels equivalent to 8fold the lipopeptide MIC for a given strain [12,19]. The relatively high protein binding and low volume of distribution of daptomycin recorded in humans or animal models represent a difficult challenge for defining a dosing schedule exerting optimal bactericidal activity against major categories of serious $S$. aureus infections [12,21-29] in various deep-seated compartments though minimizing skeletal muscle side-effects [30,31]. Another issue is the recently shown observation that pulmonary surfactant interfered with daptomycin antimicrobial activity thus providing a likely explanation for treatment failures in clinical trials of community-acquired pneumonia and animal models of gram-positive pneumonia [28].

We previously described an animal model for evaluating the in vivo activity of various bactericidal antibiotics against localized chronic foreign body infections due to $S$. aureus [32-38]. This model consists in perforated Teflon cylinders, named tissue cages, which are subcutaneously implanted in rats and infected three to four weeks after surgical implantation by percutaneous local inoculation of $10^{5} \mathrm{CFU}$ of methicillin-susceptible (MSSA) or methicil- lin-resistant (MRSA) strains of S. aureus, yielding sustained bacterial viable counts in tissue cage fluids for several weeks [32]. The presence of the inflammatory exudative fluid inside tissue cages, designated as tissue cage fluid (TCF), allows a direct assessment of the levels and pharmacokinetic properties of any antimicrobial agent that accumulates into this compartment after systemic administration. Drug efficacy is evaluated by comparing quantitative cultures of each cage fluid before and after 7 days of intensive antimicrobial therapy [32]. Several studies have shown that systemic administration of various categories of antibiotics can deliver adequate levels of antimicrobial agents in TCFs [32-36]. In those studies, the nearly continuous presence of bactericidal levels of each antimicrobial was required throughout the 7-day therapies to obtain a significant reduction of at least one $\log _{10}$ CFU of MSSA or MRSA per ml of TCF, as shown with vancomycin [32], oxacillin and imipenem [33], and several fluoroquinolones including sparfloxacin and temafloxacin [35], levofloxacin and trovafloxacin [36]. With respect to the low efficacies of 7 -day monotherapies with previously tested antimicrobial agents against $S$. aureus chronically infecting tissue cages, the concentrationdependent, highly bactericidal activity of daptomycin seemed to be promising in this model.

A first study (sponsored by Lilly and referred to as the daptomycin no 1-study) was initiated in 1991 for evaluating daptomycin in the rat model of tissue cage infections. The study protocol was composed of two arms, the first one assessing in vivo activity of daptomycin and comparators against MSSA-infected and the second one against MRSAinfected tissue cages. Because of concern with potential reduction of drug efficacy due to high protein binding, a twice-daily regimen of $30 \mathrm{mg} / \mathrm{kg}$ daptomycin was selected for the daptomycin no 1-study, which resulted in very high levels of daptomycin in TCFs and led to impressive reductions in cage fluid viable counts in the MSSA arm that was the only one to be completed. In contrast, the MRSA arm of the daptomycin no 1-study was interrupted by Lilly's decision to suspend the development and experimental testing of daptomycin, which left data from the daptomycin no 1-study essentially unpublished (excepting for a brief report) [39].

Following resumption of daptomycin clinical development by Cubist in 1997, we initiated a second study (referred to as the daptomycin no 2-study) using a modified protocol that took into consideration the lower toxicity of once-daily administration of daptomycin [30,31]. With respect to the very high levels recorded in TCFs during the daptomycin no 1-study, we anticipated that a $50 \%$ reduction in drug dosage, consisting in a single daily administration of $30 \mathrm{mg} / \mathrm{kg}$ daptomycin, would still deliver high, continuously bactericidal drug levels for 
therapy in S. aureus-infected cage fluids. Unexpectedly, the TCF levels recorded with the once-daily regimen of $30 \mathrm{mg} /$ $\mathrm{kg}$ daptomycin turned out to be much lower than those anticipated from the $50 \%$ reduction of the previously used twice-daily regimen administered in the daptomycin no 1-study [37]. While the drug levels reached in TCFs by the once-daily $30 \mathrm{mg} / \mathrm{kg}$ daptomycin regimen were still over the minimal bactericidal concentration and led to significant viable count reductions in $S$. aureus-infected cage fluids [37], those drug levels were clearly inferior to the 8-fold levels over the MIC of the infecting organism recommended for optimal daptomycin bactericidal activity against $S$. aureus $[8,9,12,21]$.

In the context of recently presented pharmacological, experimental, and clinical studies exploring the safety and efficacy of higher once-daily doses of daptomycin [29,4042] for treating serious gram-positive infections (e.g. S. aureus bacteremia, endocarditis, osteomyelitis), compared to the FDA-approved $4 \mathrm{mg} / \mathrm{kg}$ daily regimen for complicated skin and skin-structure infections (CSSSIs), the presentation of pharmacokinetic and efficacy data obtained during the daptomycin no 1-study gains increased relevance. The aims of this report are to (i) show the impact of the twice-daily $30 \mathrm{mg} / \mathrm{kg}$ daptomycin regimen in the therapy of chronically infected tissue cages compared to oxacillin and vancomycin; (ii) emphasize the major differences in TCF drug levels reached by administration of a twice-daily compared to once-daily $30 \mathrm{mg} / \mathrm{kg}$ daptomycin regimen [37]; (iii) discuss the pharmacokinetic and pharmacodynamic factors that may contribute to daptomycin efficacy in our hard-to-treat rat tissue cage model of foreign body infections as well as other infection models or clinical situations.

(An abstract form of this study was presented at the 42nd Intersci. Conf. Antimicrob. Agents Chemother., abstr. 1904, 2002) [39].

\section{Methods}

\section{Bacterial strain}

The methicillin-susceptible $S$. aureus (MSSA) strain I20 is a previously described clinical isolate from catheterrelated sepsis, which is highly virulent in the rat model of chronic $S$. aureus tissue cage infection $[33,43]$. Strain I20 is uniformly susceptible to all antibiotics except penicillin.

Besides the strain used for the animal study, a previously mentioned collection of $107 \mathrm{~S}$. aureus clinical strains isolated before 1991 in the University Hospital of Geneva [33] were also tested for in vitro susceptibility to daptomycin. They comprised 57 MSSA and 50 MRSA strains.

\section{Antimicrobial agents}

All experimental in vitro and in vivo results reported in the daptomycin no 1-study, also including the 107 clinical isolates tested for in vitro susceptibility, were recorded in 1991 using a single batch of quality-controlled daptomycin powder supplied by Ely Lilly (Giessen, Germany). Daptomycin solutions were freshly prepared in distilled sterile water, namely at a concentration of $5 \mathrm{mg} / \mathrm{mL}$ for in vitro studies and $7.5 \mathrm{mg} / \mathrm{L}$ for in vivo studies. Oxacillin (Sigma Chemical, St. Louis, Mi) was freshly dissolved in distilled water at a concentration of $20 \mathrm{mg} / \mathrm{ml}$. Commercially available vancomycin hydrochloride (Lilly) was solubilized as recommended by the manufacturer.

\section{In vitro studies}

The MICs of oxacillin and vancomycin for strain I20 were determined in cation-adjusted Mueller-Hinton broth (CAMHB) containing 20-25 mg/ $\mathrm{L} \mathrm{Ca}^{2+}$ and $10-12.5 \mathrm{mg} / \mathrm{L}$ $\mathrm{Mg}^{2+}$ by the standard tube macrodilution method with an average inoculum of $10^{6} \mathrm{CFU} / \mathrm{mL}$ as described by the Clinical Laboratory Standards Institute (CLSI) [44]. For daptomycin MIC, CAMHB was supplemented with additional calcium to a physiological concentration of $50 \mathrm{mg} /$ $\mathrm{L} \mathrm{Ca}^{2+}(\mathrm{CSMHB})$.

To screen for the possible carryover effects of each antibiotic during the MBC determinations, $0.1-\mathrm{mL}$ portions were taken from all tubes with no visible growth. These were subcultured, either undiluted or diluted 10 -fold in saline, on Mueller-Hinton agar (MHA) for $36 \mathrm{~h}$ at $37^{\circ} \mathrm{C}$. The MBC was defined as the lowest concentration that killed $99.9 \%$ of the original inoculum.

Each MIC and MBC determination was performed three times and the modal values are presented. In additional control experiments, MICs and MBCs were performed in CAMHB supplemented with 50\% TCF.

\section{Killing kinetic studies}

0.1-mL portions containing $10^{6}$ CFU of strain I20 (obtained from exponential-phase cultures) were added to sterile plastic tubes containing $1 \mathrm{~mL}$ of either CSMHB containing $8 \mathrm{mg} / \mathrm{L}$ of daptomycin, or CAMHB containing $8 \mathrm{mg} / \mathrm{L}$ of oxacillin or vancomycin, in a shaking waterbath at $37^{\circ} \mathrm{C}$. The number of viable organisms was determined by subculturing $50 \mu \mathrm{L}$ of 10 -fold diluted portions on MHA after 0, 2, 4, 6, and 24 h of incubation. Colonies were enumerated with a laser colony counter (Spiral System) after $48 \mathrm{~h}$ of incubation at $37^{\circ} \mathrm{C}$. The detection limit was $2 \log _{10} \mathrm{CFU} / \mathrm{mL}$. No significant carryover of antibiotics was observed by using these experimental conditions. Each killing kinetic experiment was repeated three times and results from one representative experiment are presented. 


\section{Treatment of chronic tissue cage infections}

All animal studies of the daptomycin no 1-study were performed in 1991. These animal studies followed ethical guidelines of that time period and received legal approval from the Veterinary Office of the State of Geneva. Subcutaneous surgical implantation of four tissue cages per animal was performed as described [32] by using Wistar rats that were anaesthetised with an intraperitoneal (i.p.) injection of a mixture of ketamine $(90 \mathrm{mg} / \mathrm{kg})$ and xylazine $(5 \mathrm{mg} / \mathrm{kg})$. At 3 weeks post-implantation, TCF was aspirated and checked for sterility. To establish a chronic $S$. aureus infection, tissue cages were inoculated with 0.1 $\mathrm{mL}$ of saline containing $0.2 \times 10^{6}$ to $2 \times 10^{6} \mathrm{CFU}$ of a washed overnight culture of strain I20 in CAMHB. Three weeks later, all tissue cages containing more than $10^{5}$ $\mathrm{CFU} / \mathrm{mL}$ of TCF were included in the therapeutic protocols.

Rats infected with strain 120 were randomised to receive (by the i.p. route for 7 days) twice-daily regimens of either daptomycin $(30 \mathrm{mg} / \mathrm{kg})$, oxacillin $(200 \mathrm{mg} / \mathrm{kg})$, or vancomycin $(50 \mathrm{mg} / \mathrm{kg})$, or were left untreated. At $12 \mathrm{~h}$ after the last injection of antibiotic, quantitative cultures of 10 -fold serially diluted TCF were performed on MHA. To optimise the yield of viable bacteria, TCF were briefly sonicated (60 $\mathrm{W}, 1 \mathrm{~min}$ ) to disrupt the biofilm and phagocytic cells before the serial dilutions and plating. Plates were incubated for $24-48 \mathrm{~h}$ at $37^{\circ} \mathrm{C}$. The detection limit was one colony equivalent to $2 \log _{10} \mathrm{CFU} / \mathrm{mL}$ of TCF. The differences in CFU counts between day 1 and day 8 were determined and expressed as delta $\log _{10} \mathrm{CFU} / \mathrm{mL}$. For each treatment group, results were expressed as means \pm standard errors of the means (SEM). Comparison of bacterial counts in the different groups was performed by ANOVA and Newman-Keuls multiple comparisons procedures using Microsoft Excel ${ }^{\circledR} 2000$ software [45]. Data were considered significant when $P$ was $<0.05$ by using two-tailed significance levels.

To check for potential side effects of the twice-daily 30 $\mathrm{mg} / \mathrm{kg}$ daptomycin regimen, serum samples of the daptomycin-treated and control rats were collected at day 8 for determination of liver, kidney, and muscle enzyme markers, namely aspartate aminotransferase (ASAT) and alanine aminotransferase (ALAT) activities, serum creatinine, and creatine kinase, respectively, using standard analytical methods.

\section{Pharmacokinetics of antimicrobial agents}

The pharmacokinetic levels of daptomycin were determined in TCF of uninfected rats, at various time intervals $(0,2,4,6$, and $12 \mathrm{~h})$ on day 4 and day 7 of twice-daily administration of $30 \mathrm{mg} / \mathrm{kg}$ daptomycin as described in the daptomycin no 2-study [37]. S. aureus-infected tissue cage fluids were not assayed to avoid potential interfer- ence with the daptomycin microbiological assay and minimize plasma contamination of TCF samples. Plasma daptomycin levels were determined on rat blood also collected from uninfected rats by periorbital puncture at various time intervals $(0.25,0.5,1,2,4,6,8$, and $12 \mathrm{~h})$ after i.p. administration of this antibiotic. For each time point, the mean $( \pm$ SEM) daptomycin levels in plasma from four animals was determined.

The concentrations of daptomycin in rat plasma or TCF were estimated by a previously described microbiological assay [46] excepting for the use of Antibiotic medium 11 and Sarcina lutea as the test strain [37]. To avoid a potential bias due to protein binding, all plasma or TCF samples were diluted with 1 volume of PBS and assayed in duplicate, with reference to a range of standard concentrations (1-128 $\mathrm{mg} / \mathrm{L})$ of daptomycin, also prepared in duplicate in PBS supplemented with $50 \%$ plasma or TCF, respectively. The correlation coefficients of daptomycin standard curves were generally $\geq 0.99$, yielding intra-assay CVs of $\pm 10 \%$. Under these experimental conditions, the limit of detection of the daptomycin assay was $1 \mathrm{mg} / \mathrm{L}$. For each time point, the mean $( \pm$ SEM) daptomycin levels in TCF from six animals were determined.

The areas under the concentration-time curve (AUC) of daptomycin in rat plasma or TCF were estimated from 0 to $12 \mathrm{~h}\left(\mathrm{AUC}_{0-12}\right)$ by the linear trapezoidal rule. For comparison with a previously reported $\mathrm{AUC}_{0-24}$ in the daptomycin no 2-study, under a once-daily $30 \mathrm{mg} / \mathrm{kg}$ daptomycin regimen [37], we multiplied the $\mathrm{AUC}_{0-12}$ estimated from the twice-daily daptomycin regimen by a factor of two.

The pharmacokinetic properties of oxacillin [33] and vancomycin [32] in rat tissue cage fluid were previously described.

\section{Results and discussion In vitro studies}

The MIC and MBC of daptomycin in CSMHB for MSSA I20 were 0.5 and $1 \mathrm{mg} / \mathrm{L}$, respectively. The MICs and MBCs of oxacillin or vancomycin in CAMHB for MSSA I20 were 0.5 and 1 or 1 and $2 \mathrm{mg} / \mathrm{L}$, respectively.

The MICs of daptomycin for 107 clinical isolates tested with the same batch of daptomycin as used for the rat tissue cage study were very similar to those reported 10 years later using more recent daptomycin batches [11,15-18]. Daptomycin MICs were $0.5,1$, and $2 \mathrm{mg} / \mathrm{L}$ for 5,98 , and 4 isolates, respectively. These data assessed that the antimicrobial potency of daptomycin used in the daptomycin no 1-study was equivalent to that used 10 years later for the daptomycin no 2-study [37]. 


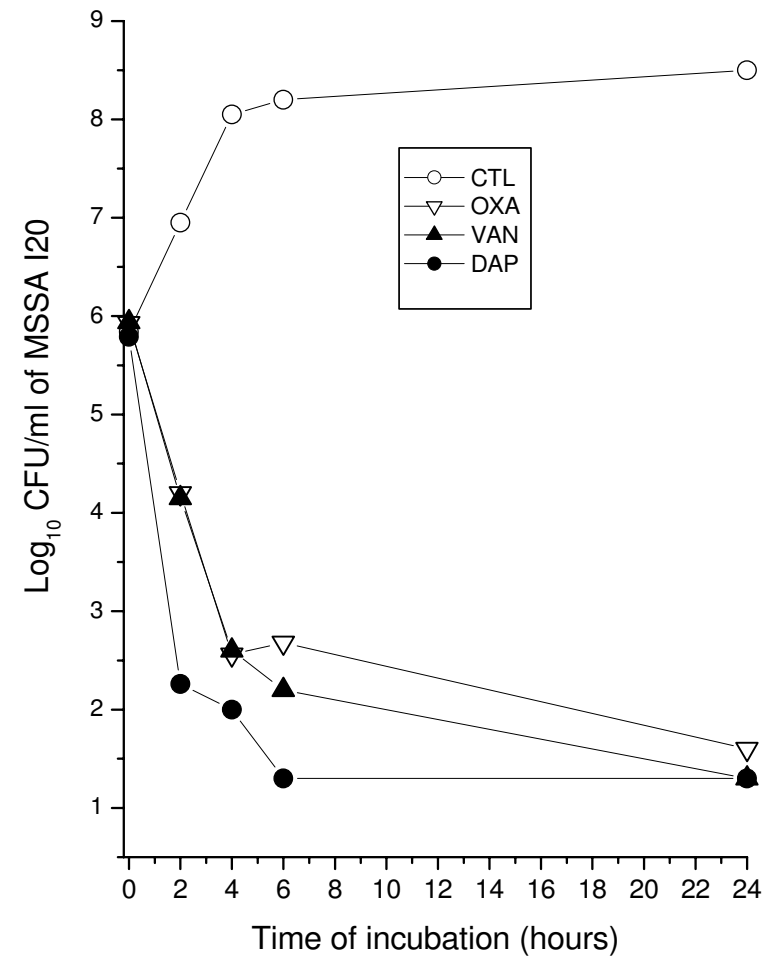

\section{Figure I}

Elimination rates of methicillin-susceptible S. aureus (MSSA) strain 120 with daptomycin (DAP; $8 \mathrm{mg} / \mathrm{L}$ ), oxacillin (OXA; 8 $\mathrm{mg} / \mathrm{L}$ ) or vancomycin (VAN; $8 \mathrm{mg} / \mathrm{L})$, assayed in CSMHB (DAP) or CAMHB (OXA; VAN). These data are from a single representative experiment and were reproduced three times.

The in vitro elimination rate of exponentially grown MSSA I20 was more rapid with $8 \mathrm{mg} / \mathrm{L}$ of daptomycin than with equivalent concentrations of oxacillin or vancomycin (Figure 1). The reduction in the viable counts of strain I20 by daptomycin, oxacillin, and vancomycin exceeded $3 \log _{10} \mathrm{CFU} / \mathrm{mL}$ after 2, 4 , and $4 \mathrm{~h}$, respectively. The more rapid bactericidal activity of daptomycin over oxacillin and vancomycin was reproduced in three independent experiments.

The elimination rate of MSSA I20 by daptomycin was not significantly affected by supplementation of CSMHB with $50 \%$ TCF (data not shown).

\section{Treatment of chronic tissue cage infections}

At the onset of therapy, average bacterial counts for 74 cages infected with MSSA I20 were $6.85 \pm 0.25 \mathrm{CFU} / \mathrm{mL}$ for controls $(n=19), 6.61 \pm 0.19 \log _{10} \mathrm{CFU} / \mathrm{mL}$ for animals receiving daptomycin $(n=18), 6.82 \pm 0.20 \log _{10}$
$\mathrm{CFU} / \mathrm{mL}$ for animals receiving oxacillin $(\mathrm{n}=18)$, and 6.46 $\pm 0.20 \log _{10} \mathrm{CFU} / \mathrm{mL}$ for animals receiving vancomycin $(\mathrm{n}$ $=19$ ). These four sets of bacterial counts did not differ significantly from one other.

At the end of the 7-day therapy, average counts in tissue cages of control, daptomycin-treated, oxacillin-treated, and vancomycin-treated animals were $7.33 \pm 0.14(\mathrm{n}=$ 19), $3.99 \pm 0.34(\mathrm{n}=18), 5.90 \pm 0.25(\mathrm{n}=18)$, and 5.49 $\pm 0.21 \log _{10} \mathrm{CFU} / \mathrm{mL}(\mathrm{n}=19)$, respectively. Compared to the control group that showed a slight albeit non-significant increase of $0.48 \pm 0.24 \log _{10} \mathrm{CFU} / \mathrm{mL}$, all antibiotic regimens led to significant $(P<0.001)$ reductions in bacterial counts in TCF, namely $2.62 \pm 0.31 \mathrm{CFU} / \mathrm{mL}$ for animals receiving daptomycin, $0.92 \pm 0.21 \mathrm{CFU} / \mathrm{ml}$ for animals receiving oxacillin, and $0.96 \pm 0.24 \log _{10} \mathrm{CFU} / \mathrm{mL}$ for animals receiving vancomycin (Figure 2). The mean reduction in CFU counts in TCF of rats treated with daptomycin was significantly $(P<0.01)$ higher $(>2$-fold) than that of oxacillin- or vancomycin-treated animals.

\section{Pharmacokinetic properties of daptomycin in plasma and tissue cage fluid}

The pharmacokinetic levels of daptomycin in rat plasma on day 4 of daptomycin therapy are shown on Figure 3. On day 4 of administration with twice-daily doses (30 $\mathrm{mg} / \mathrm{kg}$ ) of daptomycin, mean peak and trough plasma levels were 173 and $9.1 \mathrm{mg} / \mathrm{L}$ at $1 \mathrm{~h}$ and $12 \mathrm{~h}$, respectively. Similar concentrations of daptomycin were recorded on day 7 of therapy (data not shown). For comparison, the peak $(141 \mathrm{mg} / \mathrm{L})$ and trough $(0 \mathrm{mg} / \mathrm{L})$ plasma levels on day 4 of administration with once-daily doses $(30 \mathrm{mg} / \mathrm{kg}$ ) of daptomycin recorded in the daptomycin no 1-study [37] are represented on Figure 3. The pharmacokinetic profiles of twice-daily and once-daily regimens of daptomycin are not markedly different besides the much lower level recorded at $12 \mathrm{~h}$ for the once-daily ( $1 \mathrm{mg} / \mathrm{L})$ compared to twice-daily $(9.1 \mathrm{mg} / \mathrm{L})$ dosing. The similar pharmacokinetic profiles obtained in both independently conducted studies using two different methods, namely a microbiological assay and HPLC, provide support to the reliability of these data and further indicate that the antimicrobial potency of daptomycin used for the daptomycin no 1-study was equivalent to that used 10 years later for the daptomycin no 2-study [37]. The plasma $\mathrm{AUC}_{0-24 \mathrm{~h}}$ $(1667 \mathrm{mg} \times \mathrm{h} / \mathrm{L})$ recorded with the twice-daily regimen was $>2$-fold higher than the once-daily regimen of $30 \mathrm{mg} /$ $\mathrm{kg}$ daptomycin that yielded a plasma $\mathrm{AUC}_{0-24 \mathrm{~h}}$ of $558 \mathrm{mg}$ $\times \mathrm{h} / \mathrm{L}[37]$.

More striking differences were observed when comparing pharmacokinetic levels of daptomycin reached in rat TCF by twice-daily versus once-daily administration of this antibiotic (Figure 4). Mean peak and trough levels of daptomycin in TCF were 66 and $21 \mathrm{mg} / \mathrm{L}$ for rats receiving the 


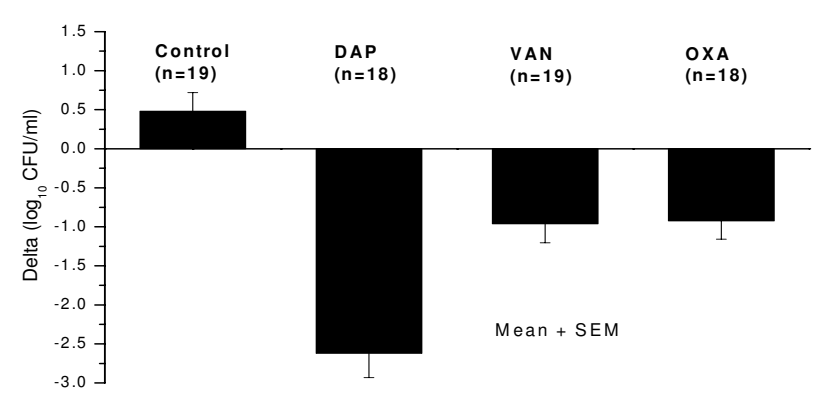

Figure 2

Decrease in viable counts of methicillin-susceptible $S$. aureus (MSSA) in tissue cage fluids of rats treated for 7 days with twice-daily regimens of either daptomycin $(30 \mathrm{mg} / \mathrm{kg})$, oxacillin $(200 \mathrm{mg} / \mathrm{kg})$, or vancomycin $(50 \mathrm{mg} / \mathrm{kg})$. $\mathrm{n}$ : number of cages included in each group.

twice-daily daptomycin regimen. In comparison, mean peak and trough TCF levels of daptomycin were 11.8 and $3.4 \mathrm{mg} / \mathrm{L}$ for rats receiving the once-daily daptomycin regimens, with an intermediate value of $10.0 \mathrm{mg} / \mathrm{L}$ at $12 \mathrm{~h}$. The most significant difference in pharmacokinetics was a ca. 5.5-fold increase in TCF $\mathrm{AUC}_{0-24 \mathrm{~h}}$ of rats receiving twice-daily (1073 mg $\times$ h/L) compared to once-daily (196 $\mathrm{mg} \times \mathrm{h} / \mathrm{L}$ ) regimens of daptomycin.

In rats receiving twice-daily doses of oxacillin $(200 \mathrm{mg} /$ $\mathrm{kg}$ ) or vancomycin $(50 \mathrm{mg} / \mathrm{kg})$, peak and trough TCF levels were 45 and 5.7 or 12 and $2 \mathrm{mg} / \mathrm{L}$, respectively, as described previously $[32,33]$.

\section{Screening of potential side effects of high-dose daptomycin}

No exterior sign of toxicity was observed on rats receiving twice-daily doses of daptomycin. There were no or only minor changes in activities of marker enzymes of daptomycin-treated $(\mathrm{n}=5)$ vs control $(\mathrm{n}=5)$ animals, namely $216 \pm 24$ vs $146 \pm 36 \mathrm{IU} / \mathrm{L}$ for ASAT, $46 \pm 9$ vs $41 \pm 11 \mathrm{IU} /$ L for ALAT, $53 \pm 5$ vs $50 \pm 5 \mu \mathrm{M} / \mathrm{L}$ for serum creatinine, and $1393 \pm 886$ vs $1349 \pm 820$ IU/L for creatine kinase, respectively. Thus, only mild liver toxicity was observed in rats treated with high-dose daptomycin.

\section{General comments}

The improved efficacy of the twice-daily $30 \mathrm{mg} / \mathrm{kg}$ daptomycin regimen compared to oxacillin $(200 \mathrm{mg} / \mathrm{kg})$ or vancomycin $(50 \mathrm{mg} / \mathrm{kg})$ in the rat model of tissue cage infections by MSSA strain I20 should be discussed in the light of recent clinical and experimental studies that explored the safety and efficacy of higher regimens of daptomycin [29,40-42] against serious S. aureus infections (e.g. bacteremia, endocarditis, osteomyelitis) compared to the FDA-approved $4 \mathrm{mg} / \mathrm{kg}$ daily regimen for CSSSIs. The in vivo activity of the twice-daily $30 \mathrm{mg} / \mathrm{kg}$ daptomycin regimen in MSSA-infected cages was impressive when compared to the repeatedly low activity of the twice-daily $200 \mathrm{mg} / \mathrm{kg}$ regimen of the reference agent oxacillin recorded in this and a previous study [37]. While promising results were also recorded in daptomycin-treated rats infected with the MRSA strain MRGR3, the inadequately low numbers of control or vancomycin-treated animals prevented statistical validation of the MRSA arm (data not shown).

The more rapid in vitro elimination rate of MSSA strain I20 by daptomycin compared to oxacillin and vancomycin may be one factor potentially explaining its improved in vivo activity over comparators against tissue cage infections by MSSA strain I20. An additional contributing factor seems to be the very high TCF antibiotic levels resulting from the twice-daily $30 \mathrm{mg} / \mathrm{kg}$ daptomycin regimen. Nevertheless, a direct comparison between $S$. aureus in vivo elimination rates recorded in the daptomycin no 1 - and -no 2 studies is not feasible and would require a correction factor accounting for the 2-fold difference in daptomycin MICs displayed by the different $S$. aureus strains used for those studies.

Despite the fact that current pharmacokinetic models do not adequately explain the widely different TCF levels recorded with the twice daily compared to once daily 30 $\mathrm{mg} / \mathrm{kg}$ daptomycin regimens, we would like to propose the following interpretation. First, the plasma $\mathrm{AUC}_{0-24 \mathrm{~h}}$ of $558 \mathrm{mg} \times \mathrm{h} / \mathrm{L}$ estimated during the daptomycin no 1 study was considered slightly higher than the average $\mathrm{AUC}_{0-24 \mathrm{~h}}$ of human volunteers receiving a clinical oncedaily dose of $4 \mathrm{mg} / \mathrm{kg}$ [37]. Since protein binding of daptomycin is comparable between rodents and humans, it has been argued that a comparison of total daptomycin concentrations is appropriate [47]. The plasma levels of the daptomycin no 1-study were also within the range of those recorded in a therapeutic rat model of MRSA endocarditis, which yielded plasma $\mathrm{AUC}_{0-24 \mathrm{~h}}$ of 278 and 605 $\mathrm{mg} \times \mathrm{h} / \mathrm{L}$ following daily doses of 25 and $40 \mathrm{mg} / \mathrm{kg}$ of daptomycin, respectively [47]. In particular, the $40 \mathrm{mg} / \mathrm{kg}$ daptomycin daily dose in rats was considered slightly inferior to the $6 \mathrm{mg} / \mathrm{kg}$ daily dose administered to humans, which was recently shown to be efficient for therapy of S. aureus bacteremia and endocarditis [40]. Furthermore, another recent study demonstrated the necessity to administer 50 and $60 \mathrm{mg} / \mathrm{kg}$ twice-daily daptomycin regimens for efficient therapy of experimental osteomyelitis in rabbits [42]. In the same line, the 


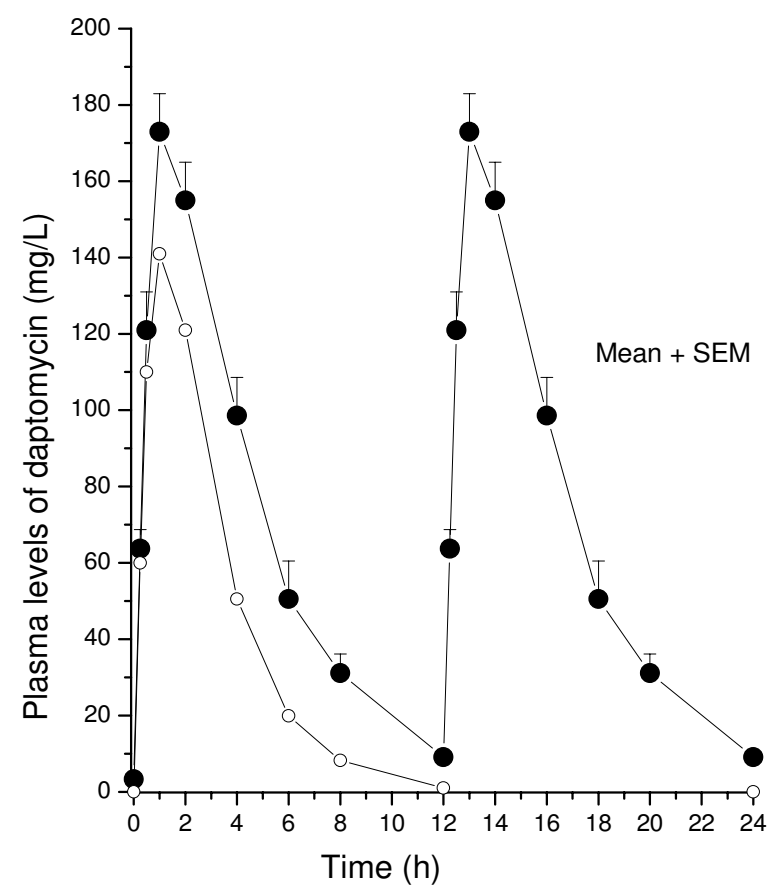

Figure 3

Pharmacokinetic levels of daptomycin in rat plasma on day 4 of therapy with twice-daily (closed symbols) or once-daily (open symbols) doses of daptomycin $(30 \mathrm{mg} / \mathrm{kg}$ ). The plasma $\mathrm{AUC}_{0-24 \mathrm{~h}}$ of rats treated with the twice-daily and once-daily regimens were 1667 and $558 \mathrm{mg} \times \mathrm{h} / \mathrm{L}$, respectively. The values for each time point are the mean (+ SEM) daptomycin plasma levels determined in four different animals.

safety and pharmacokinetics of higher daily regimens of daptomycin were also explored up to $8 \mathrm{mg} / \mathrm{kg}$ [29], and even more recently up to $12 \mathrm{mg} / \mathrm{kg}$ [41] in human volunteers.

Nevertheless, it should be stressed that it is not the plasma but the TCF $\mathrm{AUC}_{0-24 \mathrm{~h}}$ of daptomycin which is the true parameter directly influencing the therapeutic efficacy of this antibiotic at the local site of $S$. aureus infection. In the daptomycin no 1-study, the TCF $\mathrm{AUC}_{0-24 \mathrm{~h}}$ of daptomycin represented only $35 \%$ of that recorded in rat plasma, which indicated an incomplete diffusion of this antibiotic from the plasma to tissue cage fluid compartment when administered at the $30 \mathrm{mg} / \mathrm{kg}$ daily regimen [37]. In contrast, the TCF $\mathrm{AUC}_{0-24 \mathrm{~h}}$ of daptomycin administered at the
$30 \mathrm{mg} / \mathrm{kg}$ twice-daily regimen in the daptomycin no 2study was equivalent to $64 \%$ of that recorded in rat plasma. This result might be explained by either improved diffusion of this antibiotic from the plasma to TCF compartment or/and higher accumulation and slower elimination of this antibiotic in TCF compared to plasma. In this context, it should be mentioned that daptomycin pharmacokinetic parameters were shown to become nonlinear at a $8 \mathrm{mg} / \mathrm{kg}$ daily regimen including a longer halflife of elimination in human volunteers [29]. It is therefore possible that pharmacokinetic data recorded when using the twice-daily $30 \mathrm{mg} / \mathrm{kg}$ daptomycin regimen in our rat model also reflected a non-linear pharmacokinetic response compared to the daptomycin no 1-study, which was further amplified in TCF compared to plasma compartment.

Elaborated pharmacokinetic studies in the immunocompromised murine thigh model have defined the AUC/MIC ratio (range 300-1000) as the pharmacodynamic parameter most predictive of this compound's bactericidal activity against $S$. aureus [21-23]. When applied to our rat model of tissue cage $S$. aureus infections, the AUC/MIC ratio of the daptomycin no 1-study would be 98 and that of the daptomycin no 2-study 1093, which could explain the improved bacteriological result of the twice-daily over once-daily $30 \mathrm{mg} / \mathrm{kg}$ daptomycin regimens. Nevertheless, application to the rat model of tissue cage infections of AUC/MIC ratio breakpoints recorded in neutropenic mice models is probably not justified because of important differences between these animal models. It is noteworthy that daptomycin therapy is initiated as early as $2 \mathrm{~h}$ post $S$. aureus infection in neutropenic mice, which may still be in the range of prophylactic therapies. In contrast, antimicrobial therapy in the tissue cage model is not initiated before 2 or 3 weeks of chronic $S$. aureus infections, which more closely mimic the clinical situation of foreign body infections [1]. Finally, the impact of protein binding is less clearly established in the TCF compared to plasma compartment, since we found no significant in vitro reduction of daptomycin bactericidal activity against MSSA by $50 \%$ TCF in this and the daptomycin no 1-study [37].

\section{Conclusion}

In conclusion, our data further emphasise the value of performing experiments in animals for the primary evaluation of new therapeutic agents. Prediction of the therapeutic efficacies of various antibiotics against foreign body infections may be difficult by relying exclusively on in vitro pharmacodynamic models derived from pharmacokinetic data in the plasma compartment.

\section{Competing interests}

The author(s) declare that they have no competing interests. 


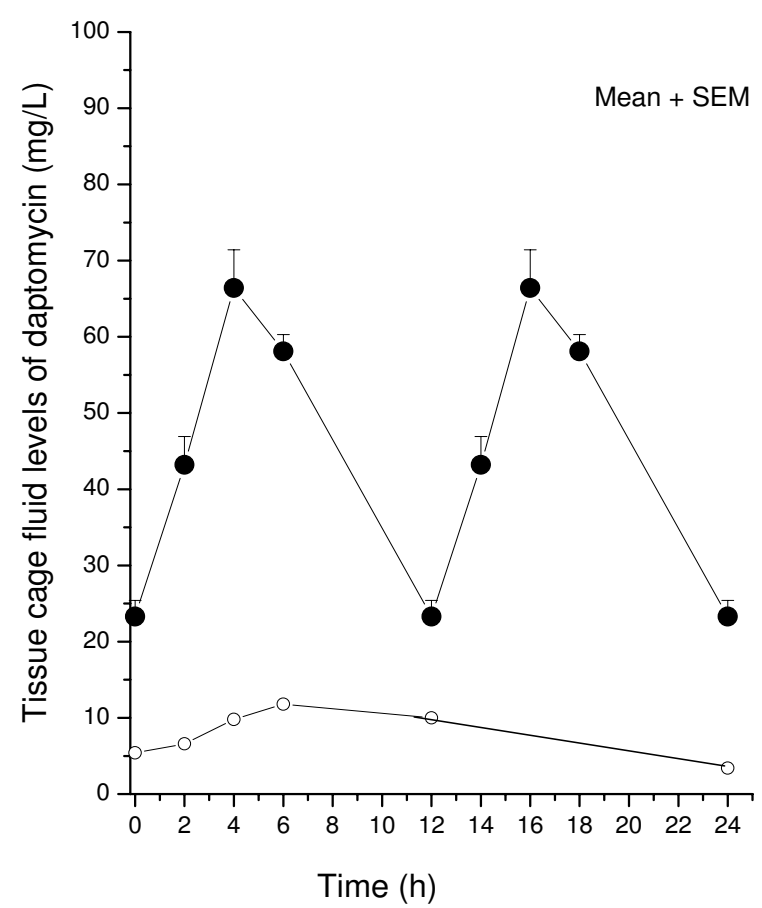

Figure 4

Pharmacokinetic levels of daptomycin in rat tissue cage fluids on day 4 of therapy with twice-daily (closed symbols) or once-daily (open symbols) doses of daptomycin $(30 \mathrm{mg} / \mathrm{kg}$ ). The tissue cage fluid $A \cup C_{0-24 h}$ of rats treated with twice-daily and once-daily regimens of daptomycin were 1073 and 196 $\mathrm{mg} \times \mathrm{h} / \mathrm{L}$, respectively. The values for each time point are the mean (+ SEM) daptomycin TCF levels determined in six different animals.

\section{Authors' contributions}

HS and DL were involved in the study design. HS and MB performed the experimental study and acquisition of data. HS and PV performed data analysis and PV wrote the final draft of this paper. HS and DL provided input into subsequent drafts and iteration of this manuscript. All authors read and approved the final manuscript.

\section{Acknowledgements}

This study was initiated by a research grant from Ely Lilly from I 990 to 1991 and is currently supported by grants 3200B0-10395 I and 3200B0-10840 I from the Swiss National Science Foundation.

\section{References}

I. Waldvogel FA, Bisno AL: Infections associated with indwelling medical devices 3rd edition. Edited by: Waldvogel FA and Bisno AL. Washington, DC, American Society for Microbiology; 2000: I-436.

2. Diekema DJ, Pfaller MA, Schmitz FJ, Smayevsky J, Bell J, Jones RN, Beach M, SENTRY PG: Survey of infections due to Staphyloco- ccus species: frequency of occurrence and antimicrobial susceptibility of isolates collected in the United States, Canada, Latin America, Europe, and the Western Pacific region for the SENTRY Antimicrobial Surveillance Program, 1997. 1999. Clin Infect Dis 200I, 32:SII4-SI32.

3. Lowy FD: Antimicrobial resistance: the example of Staphylococcus aureus. J Clin Invest 2003, I I I: | 265- | 273.

4. Chambers HF: The changing epidemiology of Staphylococcus aureus? Emerg Infect Dis 200I, 7:178-182.

5. Hiramatsu K: Vancomycin-resistant Staphylococcus aureus: a new model of antibiotic resistance. Lancet Infect Dis 200I, I:| $47-155$.

6. Liu C, Chambers HF: Staphylococcus aureus with heterogeneous resistance to vancomycin: epidemiology, clinical significance, and critical assessment of diagnostic methods. Antimicrob Agents Chemother 2003, 47:3040-3045.

7. Chang S, Sievert DM, Hageman JC, Boulton ML, Tenover FC, Downes FP, Shah S, Rudrik JT, Pupp GR, Brown WJ, Cardo D, Fridkin SK: Infection with vancomycin-resistant Staphylococcus aureus containing the vanA resistance gene. N Engl J Med 2003, 348: $1342-1347$

8. Carpenter CF, Chambers HF: Daptomycin: another novel agent for treating infections due to drug-resistant gram-positive pathogens. Clin Infect Dis 2004, 38:994-1000.

9. Steenbergen JN, Alder J, Thorne GM, Tally FP: Daptomycin: a lipopeptide antibiotic for the treatment of serious Grampositive infections. J Antimicrob Chemother 2005, 55:283-288.

10. Hancock RE: Mechanisms of action of newer antibiotics for Gram-positive pathogens. Lancet Infect Dis 2005, 5:209-2I8.

II. Schriever CA, Fernandez C, Rodvold KA, Danziger LH: Daptomycin: a novel cyclic lipopeptide antimicrobial. Am J Health Syst Pharm 2005, 62: I I45-II58.

12. Tally FP, DeBruin MF: Development of daptomycin for Grampositive infections. J Antimicrob Chemother 2000, 46:523-526.

13. Arbeit RD, Maki D, Tally FP, Campanaro E, Eisenstein BI: The safety and efficacy of daptomycin for the treatment of complicated skin and skin-structure infections. Clin Infect Dis 2004, 38:1673-168I.

14. Silverman JA, Perlmutter NG, Shapiro HM: Correlation of daptomycin bactericidal activity and membrane depolarization in Staphylococcus aureus. Antimicrob Agents Chemother 2003, 47:2538-2544.

15. King A, Phillips I: The in vitro activity of daptomycin against 5 I 4 Gram-positive aerobic clinical isolates. J Antimicrob Chemother 200I, 48:219-223.

16. Snydman DR, Jacobus NV, McDermott LA, Lonks JR, Boyce JM: Comparative in vitro activities of daptomycin and vancomycin against resistant gram-positive pathogens. Antimicrob Agents Chemother 2000, 44:3447-3450.

17. Barry AL, Fuchs PC, Brown SD: In vitro activities of daptomycin against 2,789 clinical isolates from I I North American medical centers. Antimicrob Agents Chemother 200I, 45:1919-1922.

18. Wise R, Andrews JM, Ashby JP: Activity of daptomycin against Gram-positive pathogens: a comparison with other agents and the determination of a tentative breakpoint. J Antimicrob Chemother 200I, 48:563-567.

19. Hanberger H, Nilsson LE, Maller R, Isaksson B: Pharmacodynamics of daptomycin and vancomycin on Enterococcus faecalis and Staphylococcus aureus demonstrated by studies of initial killing and postantibiotic effect and influence of $\mathrm{Ca} 2+$ and albumin on these drugs. Antimicrob Agents Chemother I991, 35:1710-1716.

20. Fuchs PC, Barry AL, Brown SD: In vitro bactericidal activity of daptomycin against staphylococci. J Antimicrob Chemother 2002, 49:467-470.

21. Safdar N, Andes D, Craig WA: In vivo pharmacodynamic activity of daptomycin. Antimicrob Agents Chemother 2004, 48:63-68.

22. Louie A, Kaw P, Liu W, Jumbe N, Miller MH, Drusano GL: Pharmacodynamics of daptomycin in a murine thigh model of Staphylococcus aureus infection. Antimicrob Agents Chemother 200I, 45:845-85।

23. Dandekar PK, Tessier PR, Williams P, Nightingale $\mathrm{CH}$, Nicolau DP: Pharmacodynamic profile of daptomycin against Enterococcus species and methicillin-resistant Staphylococcus aureus in a murine thigh infection model. J Antimicrob Chemother 2003 , 52:405-4II. 
24. Kennedy S, Chambers HF: Daptomycin (LYI 46032) for prevention and treatment of experimental aortic valve endocarditis in rabbits. Antimicrob Agents Chemother 1989, 33:1522-1525.

25. Cantoni L, Glauser MP, Bille J: Comparative efficacy of daptomycin, vancomycin, and cloxacillin for the treatment of Staphylococcus aureus endocarditis in rats and role of test conditions in this determination. Antimicrob Agents Chemother 1990, 34:2348-2353.

26. Kaatz GW, Seo SM, Reddy VN, Bailey EM, Rybak MJ: Daptomycin compared with teicoplanin and vancomycin for therapy of experimental Staphylococcus aureus endocarditis. Antimicrob Agents Chemother 1990, 34:2081-2085.

27. Voorn GP, Kuyvenhoven J, Goessens WH, Schmal-Bauer WC, Broeders $\mathrm{PH}$, Thompson J, Michel MF: Role of tolerance in treatment and prophylaxis of experimental Staphylococcus aureus endocarditis with vancomycin, teicoplanin, and daptomycin. Antimicrob Agents Chemother 1994, 38:487-493.

28. Silverman JA, Mortin LI, Vanpraagh AD, Li T, Alder J: Inhibition of daptomycin by pulmonary surfactant: in vitro modeling and clinical impact. J Infect Dis 2005, | 9 I:2 |49-2 I52.

29. Dvorchik BH, Brazier D, DeBruin MF, Arbeit RD: Daptomycin pharmacokinetics and safety following administration of escalating doses once daily to healthy subjects. Antimicrob Agents Chemother 2003, 47:1318-1323.

30. Oleson FBJ, Berman CL, Kirkpatrick JB, Regan KS, Lai JJ, Tally FP: Once-daily dosing in dogs optimizes daptomycin safety. Antimicrob Agents Chemother 2000, 44:2948-2953.

31. Tally FP, Zeckel ML, Wasilewski M, Carini C, Berman CL, Drusano GL, Oleson FBJ: Daptomycin: a novel agent for Gram-positive infections. Experimental Opinion on Investigational Drugs 200I, 8:1223-1238.

32. Lucet JC, Herrmann M, Rohner P, Auckenthaler R, Waldvogel FA, Lew DP: Treatment of experimental foreign body infection caused by methicillin-resistant Staphylococcus aureus. Antimicrob Agents Chemother 1990, 34:2312-2317.

33. Schaad HJ, Chuard C, Vaudaux P, Rohner P, Waldvogel FA, Lew DP: Comparative efficacies of imipenem, oxacillin and vancomycin for therapy of chronic foreign body infection due to methicillin- susceptible and -resistant Staphylococcus aureus. I Antimicrob Chemother 1994, 33:1।91-1200.

34. Schaad HJ, Chuard C, Vaudaux P, Waldvogel FA, Lew DP: Teicoplanin alone or combined with rifampin compared with vancomycin for prophylaxis and treatment of experimental foreign body infection by methicillin-resistant Staphylococcus aureus. Antimicrob Agents Chemother 1994, 38:1703-I710.

35. Cagni A, Chuard C, Vaudaux P, Schrenzel J, Lew DP: Comparison of sparfloxacin, temafloxacin, and ciprofloxacin for prophylaxis and treatment of experimental foreign-body infection by methicilin-resistant Staphylococcus aureus. Antimicrob Agents Chemother 1995, 39:1655-1660.

36. Vaudaux P, Francois P, Bisognano C, Schrenzel J, Lew DP: Comparison of levofloxacin, alatrofloxacin, and vancomycin for prophylaxis and treatment of experimental foreign-bodyassociated infection by methicillin-resistant Staphylococcus aureus. Antimicrob Agents Chemother 2002, 46: I503-I509.

37. Vaudaux P, Francois P, Bisognano C, Li D, Lew DP, Schrenzel J: Comparative efficacy of daptomycin and vancomycin in the therapy of experimental foreign body infection due to Staphylococcus aureus. J Antimicrob Chemother 2003, 52:89-95

38. Vaudaux P, Gjinovci A, Bento M, Li D, Schrenzel J, Lew DP: Intensive therapy with ceftobiprole medocaril of experimental foreign-body infection by methicillin-resistant Staphylococcus aureus. Antimicrob Agents Chemother 2005, 49:3789-3793.

39. Vaudaux P, Schaad H, Francois P, Bisognano C, Chuard C, Schrenzel J, Lew D: Efficacy of a high dose regimen of daptomycin compared to oxacillin and vancomycin in the therapy of experimental foreign body infection due to methicillin-susceptible Staphylococcus aureus. 42nd Intersci Conf Antimicrob Agents Chemother, San Diego, CA 2002:Abstract B-274.

40. Fowler, V., Cosgrove, S., Abrutyn E, Boucher, H., Chambers, H., Corey, G., Demeyer, I., Filler, S., Levine, D., Link, A., Rupp, M., Karchmer, A.: Daptomycin vs. standard therapy for Staphylococcus aureus bacteremia and infective endocarditis. 45th Intersci Conf Antimicrob Agents Chemother, Washington, DC 2005:Abstract K426a.
4I. Benvenuto, M., Benziger, D., Yankelev, S., Summers, E., Vigliani, G. Safety and pharmacokinetics of daptomycin at doses up to 12 mg/kg daily. 45th Intersci Conf Antimicrob Agents Chemother, Washington DC 2005:Abstract LB-2.

42. Rouse MS, Piper KE, Jacobson, M.J., Steckelberg JM, Patel R: Daptomycin treatment of Staphylococcus aureus experimental chronic osteomyelitis. 45th Intersci Conf Antimicrob Agents Chemother, Washington, DC 2005:Abstract B-2008.

43. Chuard C, Lucet JC, Rohner P, Herrmann M, Auckenthaler R, Waldvogel FA, Lew DP: Resistance of Staphylococcus aureus recovered from infected foreign body in vivo to killing by antimicrobials. J Infect Dis 1991, I63:|369-1373.

44. Clinical and Laboratory Standards Institute (CLSI): Methods for dilution antimicrobial susceptibility tests for bacteria that grow aerobically. 6th. ed. Approved Standard. CLSI document M7-A6, Vol. 23. Volume 6th. ed. Approved Standard. Edited by: CLSI . Wayne, Pa.; 2003.

45. Rosner B: Fundamentals of biostatistics 3rd edition. Belmont, CA, Duxbury Press; 1990: I-655.

46. Bouchenaki N, Vaudaux P, Huggler E, Waldvogel FA, Lew DP: Successful single-dose prophylaxis of Staphylococcus aureus foreign body infection in guinea pigs by fleroxacin. Antimicrob Agents Chemother 1990, 34:21-24.

47. Sakoulas G, Eliopoulos GM, Alder J, Eliopoulos CT: Efficacy of daptomycin in experimental endocarditis due to methicillinresistant Staphylococcus aureus. Antimicrob Agents Chemother 2003, 47:|7|4-|7|8.

\section{Pre-publication history}

The pre-publication history for this paper can be accessed here:

\section{http:/www.biomedcentral.com/1471-2334/6/74/prepub}

Publish with Bio Med Central and every scientist can read your work free of charge

"BioMed Central will be the most significant development for disseminating the results of biomedical research in our lifetime. "

Sir Paul Nurse, Cancer Research UK

Your research papers will be:

- available free of charge to the entire biomedical community

- peer reviewed and published immediately upon acceptance

- cited in PubMed and archived on PubMed Central

- yours - you keep the copyright 